\title{
Evaluation of Methods to Detect Fruit Infected by Monilinia vaccinii-corymbosi in Mechanically Harvested Rabbiteye Blueberry
}

\author{
H. Scherm and W. E. Copes, Department of Plant Pathology, University of Georgia, Athens 30602
}

\begin{abstract}
Scherm, H., and Copes, W. E. 1999. Evaluation of methods to detect fruit infected by Monilinia vaccinii-corymbosi in mechanically harvested rabbiteye blueberry. Plant Dis. 83:799-805.

Blueberry fruit infected by Monilinia vaccinii-corymbosi (causal agent of mummy berry disease) are unfit for processing because of the formation of hardened structures (pseudosclerotia) within them. In commercial packinghouses in Georgia, fruit loads exceeding the tolerance level for mummy berry are appraised at lower quality grades, resulting in severe economic penalties to producers. Two methods to detect and enumerate mummy berry in blueberry loads were evaluated in the laboratory using fruit samples with known numbers of infected fruit. The first method involved destructive processing of the samples in a blender. The resulting blueberry puree was passed through a series of screens and the number of pseudosclerotia of M. vacciniicorymbosi retained on the screens assessed tactilely. The second method consisted of visual symptom assessment of intact fruit. Bias and coefficients of variation of the blender method in five experiments ranged from -63.0 to $152.4 \%$ and 6.9 to $44.1 \%$, respectively, indicating that the method was inaccurate and imprecise. Several factors probably contributed to its poor performance, including the formation of multiple fragments from single pseudosclerotia during blending and subjectivity in the tactile assessment of pseudosclerotia. Bias and coefficients of variation of the visual assessment method in four experiments ranged from -3.41 to $1.97 \%$ and 1.16 to $5.17 \%$, respectively. Thus, the visual method was considerably more accurate and more precise than the blender method. Visual assessment was further evaluated under commercial packinghouse conditions, with $>70,000$ fruit assessed individually for symptoms of mummy berry and other abnormalities. Bias ranged from -11.1 to $33.3 \%$, indicating that visual assessment was less accurate under packinghouse conditions than under laboratory conditions. This was due to the low number of infected fruit encountered in most of the loads, which resulted in large relative errors if only a single fruit was misidentified. In a two-year packinghouse survey, a high incidence of partial infection, together with successional variations in discoloration of infected portions of the fruit as the harvest season progressed, resulted in a greater variation of mummy berry symptoms than previously described.
\end{abstract}

Additional keywords: Vaccinium ashei

Blueberry production is an important component of agriculture in Georgia. The crop is grown on more than 1,700 ha statewide, with an annual value of $\$ 4.4$ to 9.3 million (3). Most of the commercial blueberry area in Georgia is planted to Vaccinium ashei Reade (rabbiteye blueberry), a species native to the southeastern United States $(4,9)$. Fruit of rabbiteye blueberry are firmer than those of other blueberry species and retain their size better when dried, making them more suitable for proc-

Corresponding author: H. Scherm

E-mail: scherm@uga.edu

Present address of W. E. Copes: Western Washington Research and Extension Center, Washington State University, Puyallup 98371

Accepted for publication 1 June 1999.

Publication no. D-1999-0706-01R

(C) 1999 The American Phytopathological Society essing into blueberry raisins. Due to the increased popularity of blueberry raisins in food products such as granola bars, pastry mixes, dried fruit mixes, and cereal products, the dried blueberry industry has expanded considerably over the past few years. Presently, about one-third of the blueberries grown in Georgia are used for raisin manufacture (1).

One of the most serious problems encountered in dried blueberries is mummy berry disease. Monilinia vaccinii-corymbosi (Reade) Honey, the causal agent of this disease, infects the stigmas of open blueberry flowers during bloom; grows through the stylar canal, invading one or several locules; and internally colonizes the developing fruit with a dense, white mycelium $(5,6,10,12,14)$. Externally, infected fruit remain symptomless during early development (green-fruit stage). Thereafter, the exocarp of infected fruit partly or entirely turns cream to salmon when healthy fruit turn blue, and gray to grayish-white at harvest $(5,6,12)$. In mature fruit, the fungal mycelium enmeshed with fruit tissue hardens and turns black, forming a pseudosclerotium. At the same time, the exocarp becomes irregularly wrinkled. These symptoms seem specific, but blueberry producers and processors have had difficulties in distinguishing mummy berry symptoms from other abnormalities, such as those caused by insect damage or drought, which can also result in discoloration, shriveling, and hardening of fruit (W. E. Copes, unpublished).

Because of their hard texture, mummy berries are unfit for processing. The packinghouse tolerance for "damaged or underdeveloped fruit" (including mummy berries) in premium grade blueberries is low (two affected fruit per $454 \mathrm{~g} ; 2$ ), and fruit loads exceeding this tolerance are appraised at lower quality grades, resulting in severe economic penalties to producers. Thus, a reliable procedure is needed to quantify disease incidence in fruit loads under commercial conditions. Blueberry packinghouses in Georgia operate an inspection system based on destructive sampling to determine mummy berry incidence: a 952-ml fruit sample is drawn from each blueberry load, the sample macerated in a blender, the resulting puree forced through a series of screens to retain "hard objects" (presumably pseudosclerotia of $M$. vaccinii-corymbosi), and the number of hard objects on the screens determined tactilely by fingertips. If more than two hard objects are detected in the sample, the load is downgraded. Although this inspection system has been used for several years, potential error sources have not been evaluated critically. These include: (i) sampling errors due to small sample size (one sample per load); (ii) sampling errors due to the use of volumetric samples rather than gravimetric samples; (iii) systematic errors inherent in the blending process (e.g., possible formation of multiple fragments from a single pseudosclerotium during blending); and (iv) subjectivity in the assessment of hard objects (e.g., differences among assessors in recognizing pseudosclerotia tactilely).

Accuracy and precision are two of the most important attributes of disease assessment systems. Accuracy is defined as the closeness between an estimate and the true value, while precision is a measure of 
the repeatability of an estimate (7). Accuracy can be expressed as bias (i.e., the deviation of the estimate from the true value). Thus, the greater the bias of a given assessment method, the less accurate it is. Similarly, the coefficient of variation (percent variation among repeated estimates) can be used to express precision: the greater the coefficient of variation, the less precise is the method.

Because of the economic significance of mummy berry disease, it is important that the reliability of the method used for appraising blueberry loads be determined. As a step toward the development of a scientifically sound inspection system, we report here the results of laboratory experiments to determine bias and coefficients of variation of the blender method for mummy berry assessment. We compare these attributes of the blender method with those of a visual symptom assessment on intact fruit. Since the latter method requires a better appreciation of the full range of mummy berry symptoms in rabbiteye blueberry, another objective of this article is to provide a more comprehensive symptom description.

\section{MATERIALS AND METHODS}

Laboratory evaluation of blender assessment method. Mechanically harvested fruit from various rabbiteye cultivars were collected from blueberry packinghouses in southern Georgia during 1996 and 1997, transported to the laboratory, and kept frozen (experiments 1, 2, and 5) or refrigerated (experiments 3 and 4) until use. Various levels of disease incidence were prepared by adding known numbers of naturally infected fruit ( 0 to 10$)$ to either a constant volume $(952 \mathrm{ml}$; experiments 1 and 2) or a constant number (500 fruit total; experiments 3 through 5) of sound, ripe fruit. Samples containing 10 immature, green fruit or 10 abnormal, uninfected fruit (shriveled fruit with dark-blue to dark-purple exocarp) were included to determine whether such fruit would form hard objects during blending that could be misidentified as pseudosclerotia.

Samples were processed in a singlespeed Waring blender fitted with a 1.2-liter glass container by adding enough water to fill approximately $75 \%$ of the container and operating the blender for $7 \mathrm{~s}$ at 20,000 $\mathrm{min}^{-1}$. The blender was emptied onto three nested brass sieves with mesh sizes of $4.75,2.36$, and $2.00 \mathrm{~mm}$, and the fruit puree was manually forced through the screens. The number of hard objects remaining on the three screens was counted; a "hard object" was defined as a structure that was tactilely perceptible and remained intact during rubbing between fingertips. Objects macroscopically identifiable as pedicels were not counted. Processing times (including cleaning of the blender and sieves with water and a brush between samples) ranged from less than 4 min to more than 12 min per sample (data not shown).

The experiment was conducted five times with three (experiments 1 and 2) or four (experiments 3 through 5) replications arranged in a randomized complete block design. All experiments were conducted such that the assessor did not know the number of mummy berries added to a given sample. Three different assessors were involved in the experiments: experiments 1 and 2 were done by the first assessor, experiments 3 and 5 by the second, and experiment 4 by the third. All assessors were trained by subjecting them to at least one preliminary run of the experiment in which the numbers of mummy berries added to each sample were known to them.

Bias was calculated for each of the five experiments as $100 \times(\beta-1)$, where $\beta$ is the slope of the linear regression of the number of hard objects recovered on the number of mummy berries added. Thus, bias is defined here as the systematic deviation from a perfect 1:1 relationship with slope $=1.0$. Positive and negative values of bias indicate over- and underestimation, respectively. The coefficient of variation was calculated for each of the five experiments as $100 \times s_{\beta} / \beta$, where $s_{\beta}$ is the standard error of $\beta$. This measure provided an estimate of the precision (repeatability) of the blender method.

Assuming a maximum acceptable mummy berry incidence of $0.5 \%$, the frequencies of type I and type II errors were calculated. A type I error was considered to have occurred each time a sample to which $\leq 2$ infected fruit had been added before blending was determined to harbor $\geq 3$ hard objects after blending; this corresponds to falsely downgrading fruit with less than $0.5 \%$ mummy berry incidence. A type II error occurred when a sample to which $\geq 3$ infected fruit had been added was assessed as containing $\leq 2$ hard objects, implying false acceptance of fruit with more than $0.5 \%$ disease incidence.

Laboratory evaluation of visual assessment method. Mechanically harvested fruit were collected from commercial packinghouses, and samples of 200 to 300 fruit with approximately similar proportions of green, red, ripe, overripe, abnormal, and infected fruit prepared. The samples were divided into 9 or 10 subsamples, and the number of mummy berries in each subsample assessed visually on intact berries by three assessors independently. At the end of the experiment, all mummy berries and all abnormal fruit were bisected to determine the true number of mummy berries based on the presence of pseudosclerotia or characteristic mycelium in the locules. Samples of presumed healthy fruit at different stages of maturity were also bisected to confirm that they were uninfected.

The experiment was conducted four times with five replications arranged in a randomized complete block design. Percent bias was calculated as $100 \times\left(m_{\mathrm{v}}-\right.$ $\left.m_{\mathrm{t}}\right) / m_{\mathrm{t}}$, where $m_{\mathrm{v}}=$ number of mummy berries per sample according to visual assessment, and $m_{\mathrm{t}}=$ true number of mummy berries (presence of pseudosclerotia or mycelium confirmed by bisection of berries). In addition, the coefficient of variation of $m_{\mathrm{v}}$ among the three assessors was calculated to measure the precision of the visual assessment method.

Packinghouse evaluation of visual assessment method. Four packinghouses in southern Georgia were surveyed in June and early July of 1997 to evaluate the visual assessment method under commercial conditions. Mechanically harvested fruit were sampled from a total of 15 pallet loads prior to sorting and grading. The loads were from various cultivars, harvest dates, farms, and counties, thus providing a wide range of disease incidence levels and symptom types. Each pallet load consisted of five stacks of trays ( 40 by 60 by $17 \mathrm{~cm}^{3}$ ) with typically 6 to 10 trays per stack; each

Table 1. Symptom types of rabbiteye blueberry fruit infected by Monilinia vaccinii-corymbosi during a survey in commercial packinghouses in southern Georgia in 1997 and $1998^{\mathrm{a}}$

\begin{tabular}{|c|c|c|c|c|}
\hline \multirow[b]{2}{*}{ Symptom type } & \multicolumn{2}{|c|}{1997} & \multicolumn{2}{|c|}{1998} \\
\hline & Number of fruit & Percent & Number of fruit & Percent \\
\hline Exocarp discretely bicolored (cream to grayish-white and blue) & 548 & 83.0 & 4,810 & 73.8 \\
\hline $\begin{array}{l}\text { Exocarp discretely bicolored (tan and green, red, or blue; or green and red or } \\
\text { blue) }\end{array}$ & 4 & 0.6 & 104 & 1.6 \\
\hline Exocarp uniformly discolored (cream to grayish-white) & 18 & 2.7 & 449 & 6.9 \\
\hline Exocarp uniformly discolored ( $\tan )$ & 77 & 11.7 & 1,066 & 16.4 \\
\hline Indistinct symptoms ${ }^{b}$ & 13 & 2.0 & 90 & 1.4 \\
\hline
\end{tabular}

${ }^{a}$ The survey involved 15 and 10 pallet loads from which $>70,000$ and $>244,000$ fruit were assessed individually for mummy berry and other abnormalities in 1997 and 1998 , respectively.

${ }^{\mathrm{b}}$ All fruit in this category were initially misidentified as being uninfected before bisection by the assessor. 
tray contained 9 to $13 \mathrm{~kg}$ of fruit. A total of 20 550-ml samples were randomly drawn from each pallet load with no more than two samples per tray. Fruit from each sample were separated into categories in the packinghouse based on visual assessment of intact fruit. These categories included two classes of presumed healthy fruit (immature, green fruit or red to blue fruit); four classes of discolored, shriveled, or hardened fruit that were visually assessed as being infected by $M$. vaccinii-corymbosi (mummy berries; Table 1); and one category of discolored, shriveled, or hardened fruit that were visually assessed as being not infected by $M$. vaccinii-corymbosi (abnormal fruit). Assessment times ranged from less than $3 \mathrm{~min}$ to more than $5 \mathrm{~min}$ per sample (data not shown).

All fruit in each mummy berry class and in the abnormal fruit category were counted and then bisected to determine the true number of mummy berries based on the presence of pseudosclerotia or mycelium in the locules. Percent bias and the frequencies of type I and type II errors were calculated as described above for laboratory visual assessment.

Variations in mummy berry symptoms were evaluated further in late May and June of 1998 at four packinghouses. Fruit from a total of 10 pallet loads were sampled prior to sorting and grading. Nine loads consisted of five stacks of trays with six to eight trays per stack. Two (sometimes four) 550-ml samples were drawn from each tray, totaling 78 to 100 samples per pallet load. One load consisted of only five trays because harvesting was discontinued due to extremely high mummy berry incidence; four samples were drawn per tray in this pallet.

\section{RESULTS}

Laboratory evaluation of blender assessment method. In all experiments,

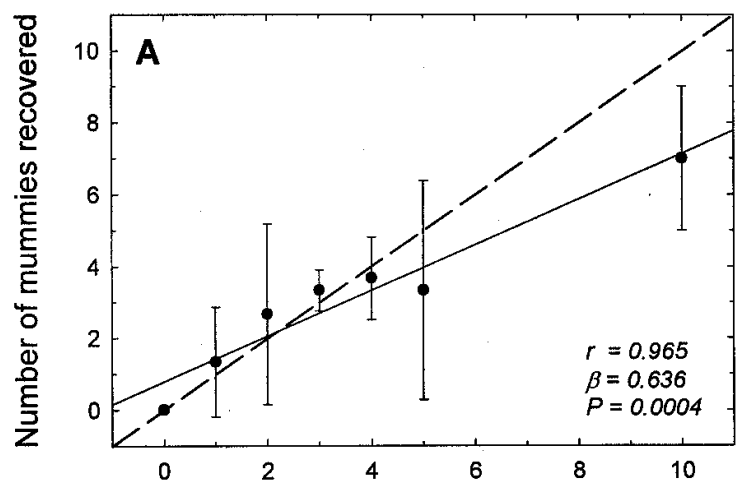

Number of mummies added

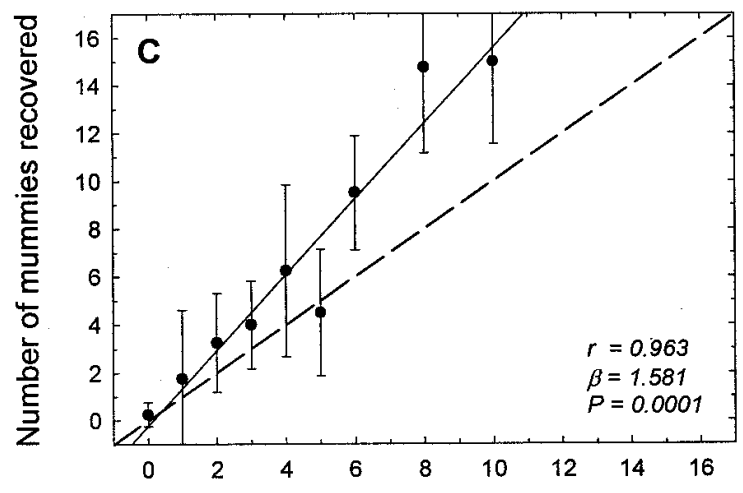

Number of mummies added

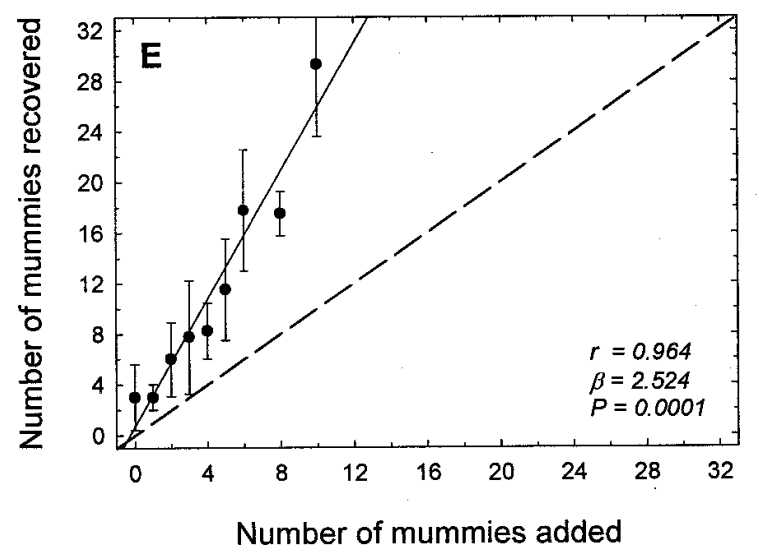

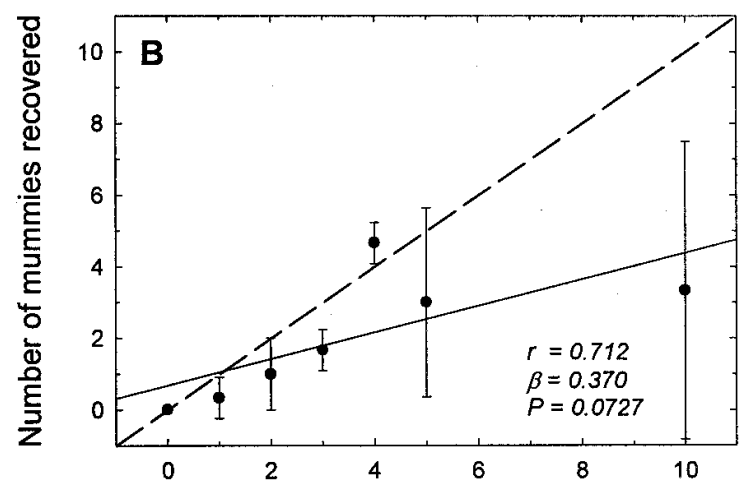

Number of mummies added

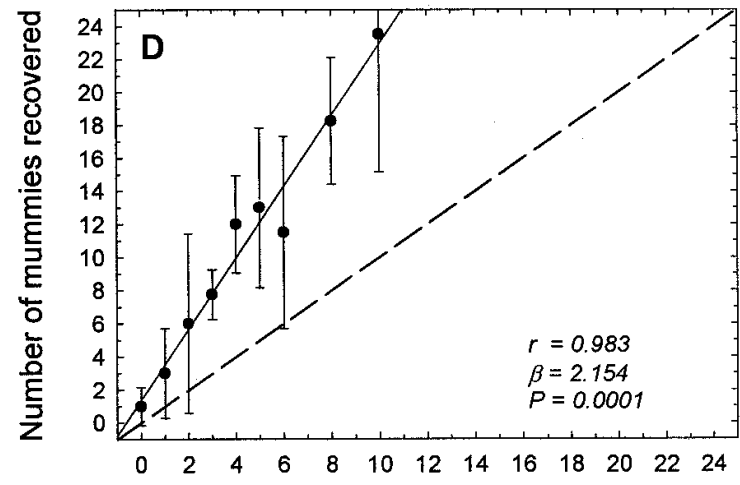

Number of mummies added

Fig. 1. Laboratory evaluation of blender method for detecting fruit infected by Monilinia vaccinii-corymbosi in rabbiteye blueberry samples. Each sample consisted of $(\mathbf{A}, \mathbf{B})$ a constant volume $(952 \mathrm{ml})$ or $(\mathbf{C}-\mathbf{E})$ a constant number $(500$ fruit total) of sound, ripe fruit containing 0 to 10 infected fruit (mummy berries). Data points are means \pm standard deviations of $(\mathbf{A}, \mathbf{B})$ three or $(\mathbf{C}-\mathbf{E})$ four replications. All linear regressions (solid lines) differed significantly $(P$ $<0.05)$ in slope from a 1:1 relationship (dashed lines). Bias $=100 \times(\beta-1)$, where $\beta=$ regression slope. 
linear relationships existed between the number of mummy berries added before blending and the number of hard objects recovered after blending (Fig. 1), showing that infected fruit were detected with the blender method. However, the slopes of the relationships differed significantly among experiments, ranging from 0.370 in experiment 2 to 2.524 in experiment 5 . Slopes also differed significantly from 1.0 in all cases $(P<0.05)$; therefore, the blender method was biased. Systematic underestimation occurred in experiments 1 and 2 (both of which were done by the same assessor), while systematic overestimation occurred in the remaining three experiments (Fig. 1). Across the five experiments, bias and coefficients of variation ranged from -63.0 to $152.4 \%$ and 6.9 to $44.1 \%$, respectively (Table 2 ).

The frequencies of type I and type II errors were calculated for a maximum acceptable mummy berry incidence of $0.5 \%$ ( $\leq 2$ infected fruit per $952-\mathrm{ml}$ or 500 -fruit sample). Of a total of 53 samples to which $\leq 2$ mummy berries had been added before blending, 19 were determined by the assessors to harbor $\geq 3$ hard objects after blending, resulting in a type I error in $35.9 \%$ of the cases (Fig. 2). Of a total of 96 samples to which $\geq 3$ infected fruit had been added, 10 were assessed to contain $\leq 2$ hard objects (type II error frequency of $10.4 \%$ ).

Samples containing 10 green fruit or 10 abnormal fruit were processed, and fragments considered hard objects by the assessors were generated from both types of fruit (Table 3). The number of hard objects recovered from samples containing 10 immature or abnormal fruit varied widely, ranging from 0 to 18.75 .

Laboratory evaluation of visual assessment method. Percent bias for visual assessment of mummy berry incidence was low, ranging from -3.41 to $1.97 \%$ across experiments and assessors (Table 4). There

Table 2. Bias and coefficient of variation (CV) of the blender method for detecting fruit infected by Monilinia vaccinii-corymbosi in rabbiteye blueberry samples ${ }^{\mathrm{a}}$

\begin{tabular}{lcrr}
\hline Experiment & Assessor & $\begin{array}{c}\text { Bias } \\
(\boldsymbol{\%})^{\mathbf{b}}\end{array}$ & \multicolumn{1}{c}{$\begin{array}{c}\text { CV } \\
(\boldsymbol{\%})^{\mathbf{c}}\end{array}$} \\
\hline 1 & A & -36.4 & 12.1 \\
2 & A & -63.0 & 44.1 \\
3 & B & 58.1 & 10.5 \\
4 & C & 115.4 & 6.9 \\
5 & B & 152.4 & 10.4 \\
\hline
\end{tabular}

${ }^{a}$ Each sample consisted of a constant volume (952 ml; experiments 1 and 2) or a constant number (500 fruit total; experiments 3 through 5) of sound, ripe fruit containing 0 to 10 infected fruit (mummy berries).

${ }^{\mathrm{b}}$ Bias $=100 \times(\beta-1)$, where $\beta$ is the slope of the linear regression of the number of hard objects recovered on the number of mummy berries added.

${ }^{\mathrm{c}} \mathrm{CV}=100 \times s_{\beta} / \beta$, where $s_{\beta}$ is the standard error of $\beta$. was no evidence for systematic over- or underestimation for any of the three assessors. The coefficient of variation among assessors ranged from 1.16 to $5.17 \%$ in the four experiments (Table 4), showing that results obtained with the visual method were relatively precise.

Packinghouse evaluation of visual assessment method. Each 550-ml sample contained between 194 and 304 fruit; thus, between 4,273 and 6,093 fruit were assessed per pallet load. Across all 15 loads, more than 70,000 fruit were assessed individually for symptoms of mummy berry and other abnormalities.

Bias for visual assessment of mummy berries ranged from -11.1 to $33.3 \%$ (Table 5), showing that the visual method was less accurate under packinghouse conditions than under laboratory conditions. Across all 15 loads, overestimation (six loads) was more frequent than underestimation (two loads), indicating that it was more likely to misidentify abnormal fruit as mummy berries than vice versa.

The frequencies of type I and II errors were calculated for a maximum acceptable mummy berry incidence of $0.5 \%(\leq 1$ infected fruit per 550-ml sample). Of a total of 222 samples containing $\leq 1$ mummy berry, three were assessed as having $\geq 2$ mummy berries, leading to a type I error in $1.35 \%$ of the cases (Fig. 3). In contrast, none of a total of 88 samples with $\geq 2$ mummy berries were assessed as having $\leq 1$ mummy berry (no type II errors).

Variation in symptoms of mummy berry disease and other abnormalities. Mummy berry symptoms encompassed a range of types (Table 1). The majority (83.0\% in 1997 and $73.8 \%$ in 1998) of infected fruit had two discretely colored (cream to gray and blue) portions of the exocarp (Fig 4C). The next most frequent

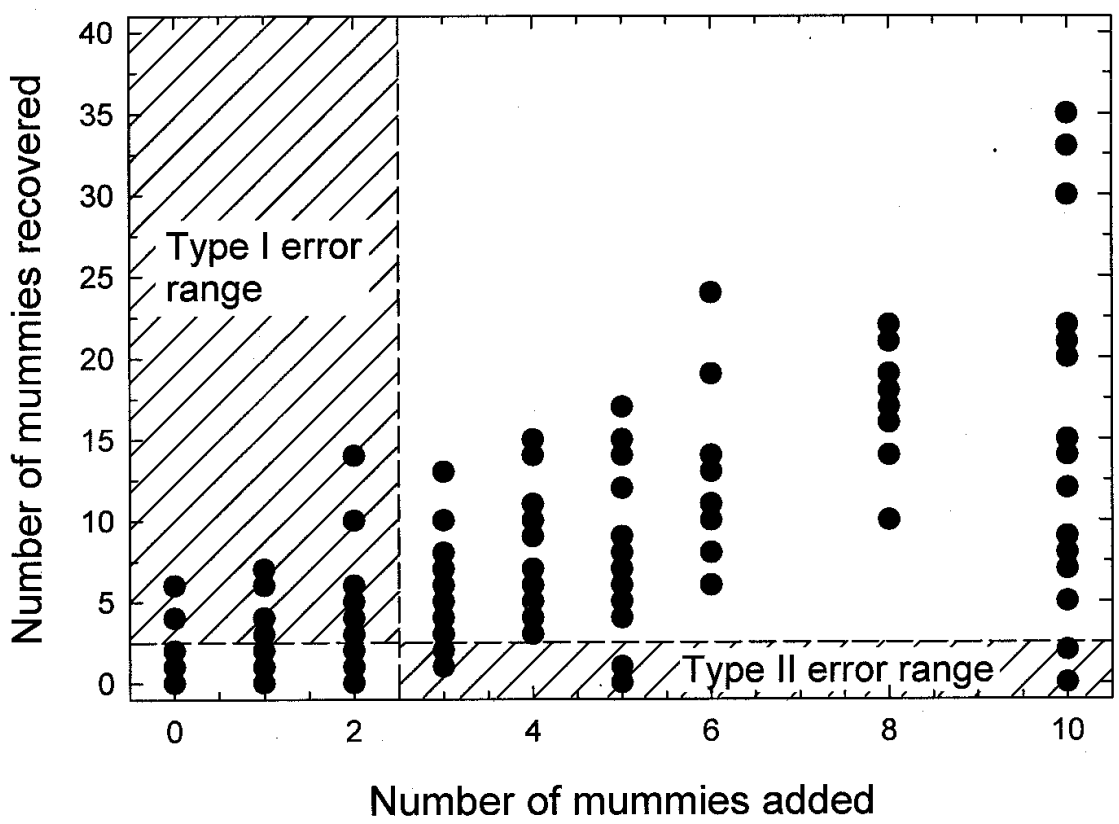

Fig. 2. Accuracy of blender method for grading rabbiteye blueberry samples when the maximum acceptable mummy berry incidence is $0.5 \%$. Each sample consisted of a constant volume $(952 \mathrm{ml})$ or a constant number (500 fruit total) of sound, ripe fruit containing 0 to 10 infected fruit (mummy berries). Error frequencies for type I errors (sample with less than $0.5 \%$ disease incidence is falsely downgraded) and type II errors (sample exceeding $0.5 \%$ disease incidence is falsely accepted) were 35.9 and $10.4 \%$, respectively. Note: some data points are hidden.

Table 3. Assessment of green fruit and abnormal fruit with the blender method for detecting fruit infected by Monilinia vaccinii-corymbosi in rabbiteye blueberry samples

\begin{tabular}{lccc}
\hline & & \multicolumn{2}{c}{ Number of hard objects recovered $^{\mathrm{a}}$} \\
\cline { 3 - 4 } Experiment & Assessor & Green fruit & Abnormal fruit $^{-}$ \\
\hline 1 & A & $0 \pm 0$ & $0.67 \pm 1.15$ \\
2 & A & $0 \pm 0$ & $0 \pm 0$ \\
3 & B & $5.75 \pm 2.87$ & $3.50 \pm 3.00$ \\
4 & C & $18.75 \pm 7.23$ & $4.75 \pm 2.50$ \\
5 & B & $14.75 \pm 2.22$ & $12.75 \pm 2.75$ \\
\hline
\end{tabular}

${ }^{a}$ Each sample consisted of a constant volume (952 ml; experiments 1 and 2) or a constant number (500 fruit total; experiments 3 through 5) of sound, ripe fruit containing 10 green fruit or 10 abnormal fruit (discolored, shriveled, or hardened fruit that were not infected by M. vaccinii-corymbosi). All values are means \pm standard deviations of three (experiments 1 and 2) or four (experiments 3 through 5) replications. 
symptom types were characterized by uniformly tan $(11.7 \%$ in 1997 and $16.4 \%$ in $1998)$ or uniformly grayish-white $(2.7 \%$ in 1997 and 6.9\% in 1998) exocarps (Fig. 4D). Variations of these types (e.g., a tan segment of exocarp surrounding the fungal tissue with either green, red, or blue segment of healthy fruit tissue; or a green segment of exocarp surrounding the fungal tissue with either red or blue segment of healthy fruit tissue) were less frequent (Fig. 4A and B). A mummy berry category with indistinct symptoms comprised a small fraction $(<2 \%)$ of the infected fruit (Table 1). The fruit in this category were all misidentified as being abnormal but uninfected based on visual assessment before bisection. Symptoms included a bicolored exocarp with poorly demarcated borders distinguishing subtle shading from blue portions to bluish gray portions or from maroon to bronzish maroon. Mummy berries were often in a size class between that of healthy fruit $(\approx 12$ to $22 \mathrm{~mm}$, depending on cultivar) and that of underdeveloped or aborted fruit $(\approx 3$ to $8 \mathrm{~mm}$; data not shown).

Most abnormal fruit that were not infected by $M$. vaccinii-corymbosi had a blue, shriveled exocarp (Fig. 4E, I, and J). Less frequent discolorations of such fruit were purple, bronze (Fig. 4F), or maroon (Fig. 4G and $\mathrm{H}$ ).

\section{DISCUSSION}

This study showed that the blenderbased mummy berry assessment method is both inaccurate and imprecise. Under ideal conditions (i.e., with samples containing only mummy berries and sound, ripe fruit), bias ranged from -63.0 to $152.4 \%$. When commercial quality criteria were applied to the laboratory samples, type I and type II error frequencies were $35.9 \%$ and $10.4 \%$, respectively. Although these errors should be cause for concern among blueberry producers and packinghouse operators, it should be noted that type I errors associated with the blender method may be lower under commercial conditions. Because packinghouse operators often do not know what defines a pseudosclerotium or how to distinguish a partial pseudosclerotium from other hard objects in a blueberry puree, they may count only the largest objects.
Table 5. Packinghouse evaluation of the visual assessment method for detecting fruit infected by Monilinia vaccinii-corymbosi in mechanically harvested rabbiteye blueberries during a survey in commercial packinghouses in southern Georgia in 1997

\begin{tabular}{lccc}
\hline Fruit load & $\begin{array}{c}\text { Mummy berry } \\
\text { incidence }(\%)\end{array}$ & $\begin{array}{c}\text { Incidence of abnormal, } \\
\text { uninfected fruit }(\%)^{\mathbf{a}}\end{array}$ & $\begin{array}{c}\text { Bias for assessment of } \\
\text { mummy berries }(\%)^{\mathbf{b}}\end{array}$ \\
\hline 1 & 0.087 & 0.229 & 0 \\
2 & 0.054 & 0.902 & 33.3 \\
3 & 6.224 & 0.583 & 4.83 \\
4 & 0.075 & 0.293 & 0 \\
5 & 0.119 & 0.640 & 25.0 \\
6 & 0.023 & 0.494 & 0 \\
7 & 0.022 & 0.209 & -11.1 \\
8 & 0.145 & 2.747 & 2.22 \\
9 & 0.856 & 0.359 & 9.09 \\
10 & 0.224 & 0.449 & 0 \\
11 & 0.438 & 0.381 & 0 \\
12 & 0.261 & 0.288 & 0 \\
13 & 0.855 & 0.578 & -0.87 \\
14 & 2.699 & 0.459 & 0.491 \\
15 & 2.444 & 0.491 & \\
\hline
\end{tabular}

${ }^{a}$ Discolored, shriveled, or hardened fruit that were not infected by $M$. vaccinii-corymbosi.

${ }^{\mathrm{b}}$ Bias $=100 \times\left(m_{\mathrm{v}}-m_{\mathrm{t}}\right) / m_{\mathrm{t}}$, where $m_{\mathrm{v}}=$ number of mummy berries according to visual, nondestructive assessment and $m_{\mathrm{t}}=$ true number of mummy berries (confirmed by bisection).

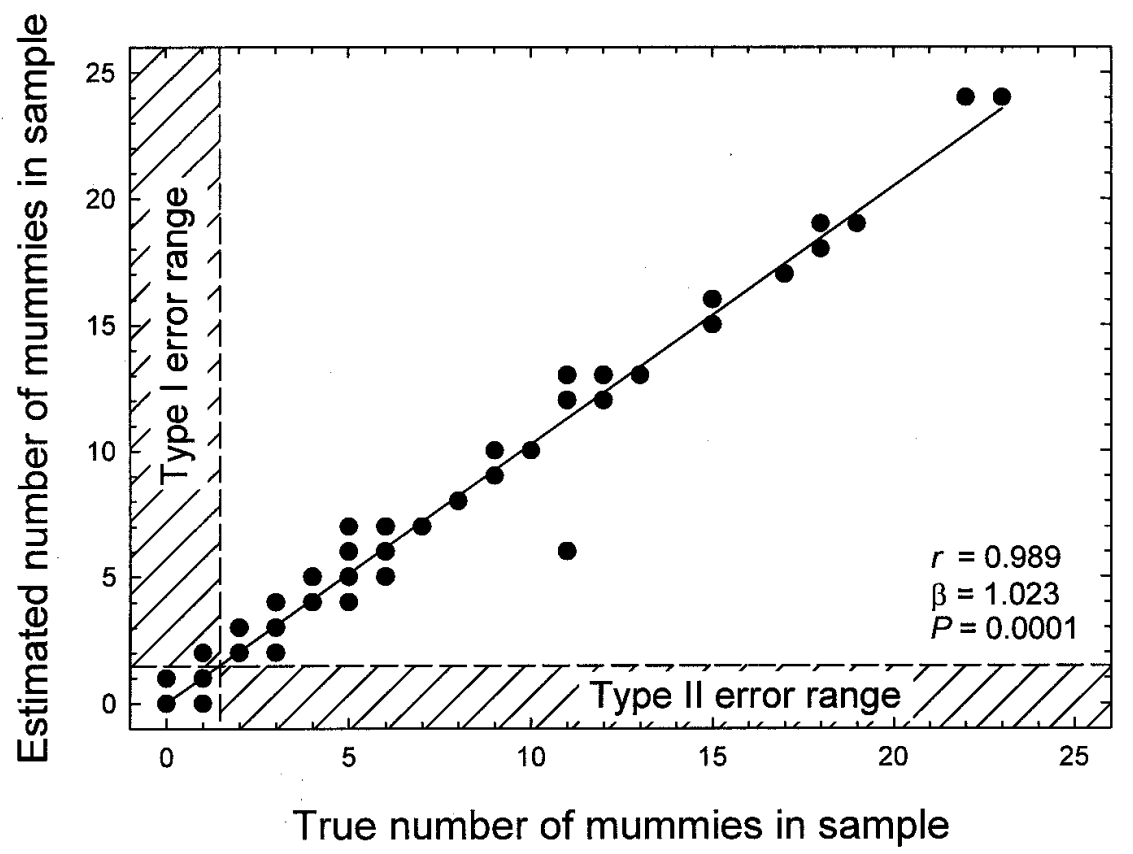

Fig. 3. Accuracy of the visual assessment method for grading of rabbiteye blueberry samples when the maximum acceptable mummy berry incidence is $0.5 \%$ (no more than one infected fruit per 550$\mathrm{ml}$ sample). Error frequencies for type I errors (sample with less than $0.5 \%$ disease incidence is falsely downgraded) and type II errors (sample exceeding $0.5 \%$ disease incidence is falsely accepted) were 1.35 and $0 \%$, respectively. Note: some data points are hidden.

Table 4. Laboratory evaluation of the visual assessment method for detecting fruit infected by Monilinia vaccinii-corymbosi in samples of rabbiteye blueberries

\begin{tabular}{llcrrr}
\hline & & \multicolumn{3}{c}{ Bias (\%) $^{\mathbf{a}}$} & \\
\cline { 3 - 5 } Experiment & \multicolumn{1}{c}{ Cultivars } & Assessor A & Assessor B & Assessor C & Coefficient of variation (\%) $^{\mathbf{b}}$ \\
\hline 1 & Climax, Brightwell & $1.97 \pm 1.38$ & $0.25 \pm 0.57$ & $1.62 \pm 1.22$ & $1.16 \pm 0.48$ \\
2 & Climax, Premier, Brightwell & $-0.17 \pm 3.18$ & $-2.28 \pm 2.43$ & $-3.41 \pm 8.93$ & $5.17 \pm 2.35$ \\
3 & Brightwell & $-1.46 \pm 2.81$ & $0.29 \pm 1.17$ & $-0.29 \pm 3.01$ & $2.03 \pm 1.47$ \\
4 & Tifblue & $0.921 \pm 4.05$ & $-0.47 \pm 1.80$ & $-1.11 \pm 4.23$ & $2.58 \pm 2.14$ \\
\hline
\end{tabular}

${ }^{\text {a }}$ Bias $=100 \times\left(m_{\mathrm{v}}-m_{\mathrm{t}}\right) / m_{\mathrm{t}}$, where $m_{\mathrm{v}}=$ number of mummy berries according to visual, nondestructive assessment and $m_{\mathrm{t}}=$ true number of mummy berries (confirmed by bisection). All values are means \pm standard deviations of five replications with $\approx 200$ to 300 fruit consisting of mummy berries mixed with green, red, ripe, overripe, and abnormal fruit.

${ }^{\mathrm{b}}$ Coefficient of variation of visual, nondestructive assessment among the three assessors. All values are means \pm standard deviations of five replications with $\approx 200$ to 300 fruit consisting of mummy berries mixed with green, red, ripe, overripe, and abnormal fruit. 
However, such underestimation would result in a greater probability of false acceptance of fruit exceeding the threshold, which could lead to increased quality problems in processing facilities that use dried blueberries, thus jeopardizing the competitiveness of blueberries from Georgia packinghouses. In our laboratory study, size was not used as a criterion for distinguishing fragments of pseudosclerotia from green or abnormal berries because small and large pieces of each tissue type were regularly detected after blending.

Three hypotheses could explain the poor results obtained with the blender method: (i) the formation during blending of multiple hard objects from single pseudosclerotia; (ii) the generation of hard objects from green or abnormal fruit; and (iii) differences among assessors in detecting hard objects tactilely. Whether over- or underestimation occurred in a given experiment was very likely determined by the balance among these three error sources. The existence of significant differences in bias among the five experiments (conducted by three different assessors) indicates that subjectivity in the tactile recognition of pseudosclerotia did indeed contribute to the variation among assessors, although the same numbers of healthy and infected fruit were used in all experiments. However, assessor effects could not be tested statistically due to the destructive nature of the assessment protocol (i.e., having the same sample tested by two or more assessors independently was impossible).

The visual assessment method was consistently more accurate and more precise than the blender method. Using visual
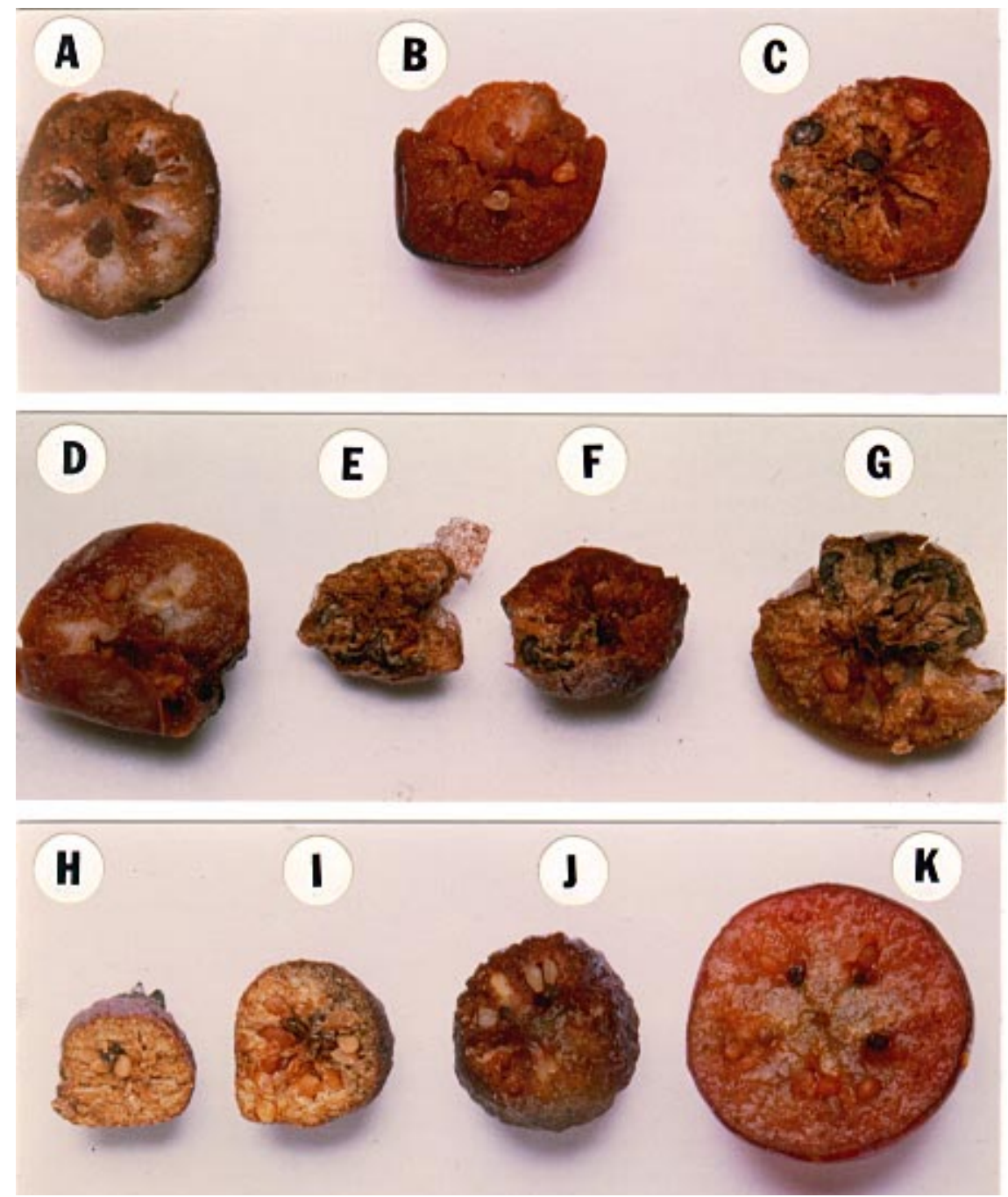

Fig. 5 Cross-sections of rabbiteye blueberry fruit $(\mathbf{A}-\mathbf{G})$ infected or $(\mathbf{H}-\mathbf{K})$ not infected with Monilinia vaccinii-corymbosi. Infected fruit contain $(\mathbf{A}, \mathbf{B}$, and $\mathbf{D})$ compact, white mycelium or $(\mathbf{C}, \mathbf{E}-\mathbf{G})$ pseudosclerotia in one or more of the locules, while $(\mathbf{H}-\mathbf{J})$ abnormal, uninfected, and $(\mathbf{K})$ healthy fruit do not

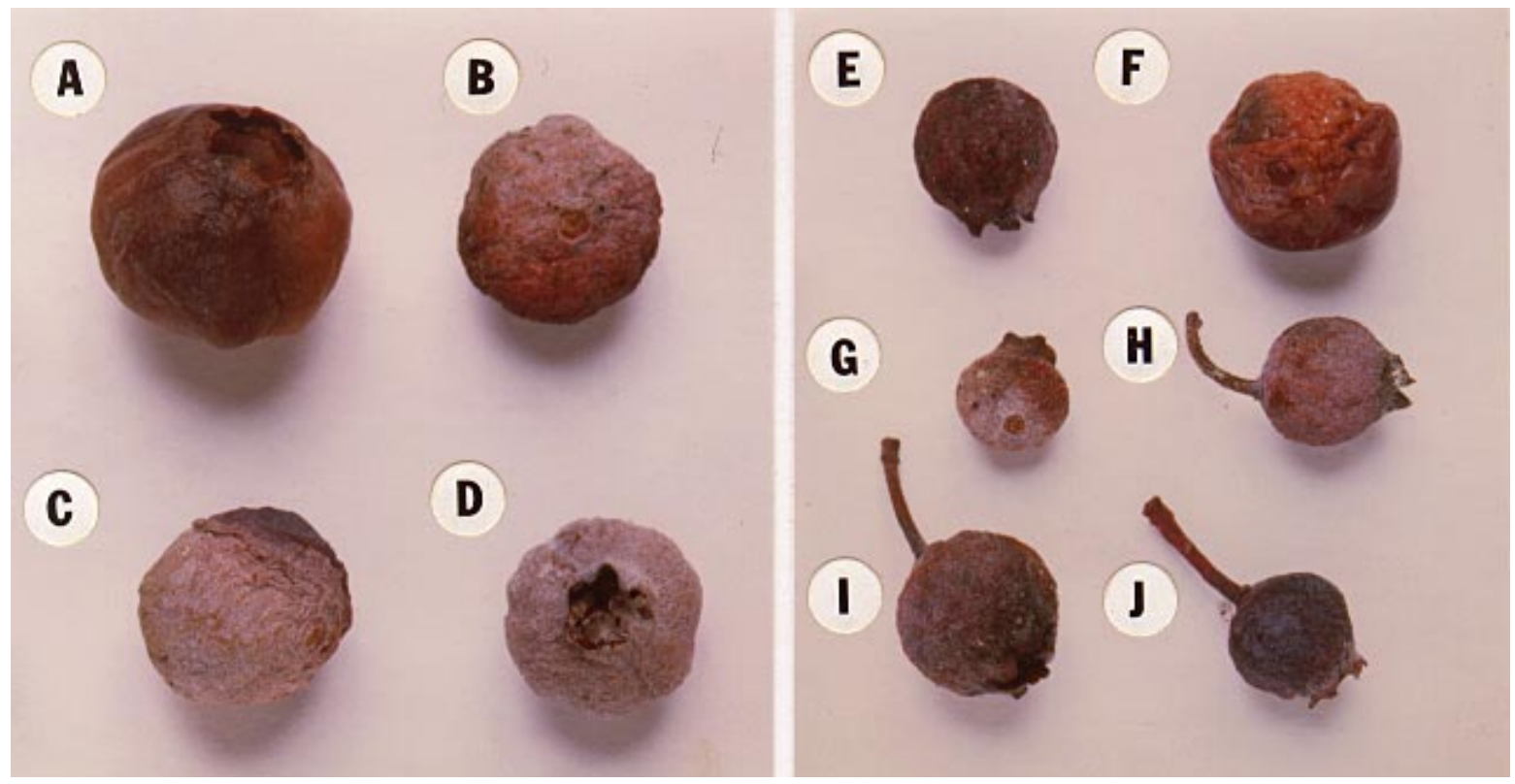

Fig. 4. Examples of symptom variability in (A-D) fruit infected with Monilinia vaccinii-corymbosi (mummy berries) and (E-J) abnormal, uninfected fruit from mechanically harvested rabbiteye blueberries in Georgia. The predominant mummy berry symptom was (C) partially infected fruit with two discretely colored (cream to grayish-white and blue) portions of the exocarp. Fruit with $(\mathbf{A}, \mathbf{B}) \tan$ or green portions of exocarp surrounding the infected tissue were less frequent, as were completely infected fruit with (D) uniformly grayish-white to tan exocarps. Most abnormal fruit had a (E, I, and $\mathbf{J})$ blue, shriveled exocarp; (F) purple, bronze, or $(\mathbf{G}, \mathbf{H})$ maroon discoloration occurred less frequently. 
assessment in the packinghouse survey, only $1.35 \%$ of the samples with less than $0.5 \%$ mummy berry incidence were falsely downgraded and none of the samples containing more than $0.5 \%$ infected fruit were falsely accepted at premium grade. Visual assessment performed even better under laboratory conditions, presumably because the low disease incidence encountered in most of the packinghouse samples resulted in larger relative errors if only a single fruit was misidentified. For example, four fruit (out of $\approx 5,600$ fruit total) were visually assessed as being infected in packinghouse load 2; following bisection, only three fruit were shown to contain pseudosclerotia or mycelium, resulting in a bias of $33.3 \%$ (Table 5).

The most common fruit symptoms of mummy berry disease were described by Batra $(5,6)$ and Milholland (12) for highbush blueberry ( $V$. corymbosum), but the range of symptom types was not emphasized. In our packinghouse survey, a high incidence of partial infection (Table 1) resulted in a greater variation of symptoms than previously described; thus, some mummy-berry symptoms were not initially recognized and contributed to the bias values in Tables 4 and 5. Additional variation in symptoms appeared to result from unsynchronized development of fungal and host tissue during the final phases of fruit maturation. Partial or complete tan or green discoloration due to infection by $M$. vaccinii-corymbosi during early harvest advanced to the more prevalent symptom (partial cream to gray discoloration) as the harvest season progressed. However, fruit of rabbiteye blueberries mature and are harvested over a period of several weeks; therefore, different symptom types can occur simultaneously. Tan and green discoloration was more prevalent in 1998 (Table 1), in which year the survey was begun earlier than in 1997.

Because of the range of mummy berry symptom types encountered in rabbiteye blueberries, and because some abnormal, uninfected fruit resemble mummy berry, there is potential for errors with the visual inspection protocol. However, if uncertainty exists whether a given fruit is infected, errors can be reduced considerably by bisecting the fruit to verify the presence of a pseudosclerotium or fungal mycelium (Fig. 5). Clearly, training would be re- quired before all packinghouse operators could reliably identify all mummy berry symptoms. This could be accomplished through publication of a pictorial key that illustrates the variability in symptoms of mummy berry disease and highlights the differences between infected fruit and other fruit abnormalities.

In most previous comparisons of disease detection methods, the same samples were used to evaluate the different techniques under investigation, thus allowing for the direct statistical comparison of their performance $(8,13,15)$. This was not feasible in the present study. Indeed, an objective assessment would have been impossible if manipulated samples (e.g., a known number of mummy berries in 500 fruit total, as used with the blender method) had been used for evaluating the visual method. This is because the preparation of a manipulated sample would have required visual selection of infected fruit to be included in the sample, thus inadvertently selecting for an easily recognizable symptom type. Further, as shown in the packinghouse survey, the most critical issue in visual assessment is not the distinction between mummy berries and sound, ripe fruit, but the distinction between mummy berries and abnormal, uninfected fruit. Conversely, the blender method could not have been evaluated without the use of manipulated samples containing only sound, ripe fruit together with mummy berries. This is because verifying the true number of infected fruit in a field sample after blending would have been impossible due to the destructive nature of the procedure. Nevertheless, although the two assessment methods could not be compared statistically due to the use of different types of samples, the differences in bias and coefficients of variation between them were large and consistent, thus allowing firm conclusions to be drawn about their relative suitability for commercial conditions.

Further research to develop a scientifically sound blueberry inspection system will focus on developing a pictorial key to aid packinghouse operators in distinguishing mummy berries from abnormal, uninfected fruit and on optimizing sampling procedures (sampling strategy, number of samples, and sample size needed to obtain a given level of precision; 11) for the visual assessment method.

\section{ACKNOWLEDGMENTS}

We thank D. Stanaland for help in collecting mummy berries and communicating with producers in southern Georgia; A. Savelle for technical and supervisory assistance in the laboratory; and C. Hutton, J. Shepherd, and L. Stoudenmire for technical assistance.

\section{LITERATURE CITED}

1. Anonymous. 1997. Dried blueberries giving raisins competition. Ga. Dep. Agric., Farmers Consum. Mark. Bull. 80(51):1, 12.

2. Anonymous. 1997. MBG Marketing 1997 Processors Handbook. MBG Marketing, Grand Junction, MI.

3. Anonymous. 1999. Noncitrus Fruits and Nuts, 1998 Preliminary Summary. USDA-NASS Fr. Nt. 1-3 (99), Washington, DC.

4. Austin, M. E. 1994. Rabbiteye Blueberries. Development, Production and Marketing. Agscience Inc., Auburndale, FL.

5. Batra, L. R. 1983. Monilinia vaccinii-corymbosi (Sclerotiniaceae): Its biology on blueberry and comparison with related species. Mycologia 75:131-152.

6. Batra, L. R. 1991. World Species of Monilinia (Fungi): Their Ecology, Biosystematics and Control. J. Cramer, Berlin, Germany.

7. Campbell, C. L., and Madden, L. V. 1990. Introduction to Plant Disease Epidemiology. John Wiley and Sons, New York.

8. Forbes, G. A., and Jeger, M. J. 1987. Factors affecting the estimation of disease intensity in simulated plant structures. Z. Pflanzenkr. Pflanzenschutz 94:113-120.

9. Hancock, J. F. 1995. Introduction: The taxonomy, botany and culture of Vaccinium. Pages 1-5 in: Compendium of Blueberry and Cranberry Diseases. F. L. Caruso and D. C. Ramsdell, eds. APS Press, St. Paul, MN.

10. Hildebrand, P. D., Milholland, R. D., and Stretch, A. W. 1995. Mummy berry. Pages 1112 in: Compendium of Blueberry and Cranberry Diseases. F. L. Caruso and D. C. Ramsdell, eds. APS Press, St. Paul, MN.

11. Marois, J. J., Bledsoe, A. M., Ricker, R. W., and Bostock, R. M. 1993. Sampling for Botrytis cinerea in harvested grape berries. Am. J. Enol. Vitic. 44:261-265.

12. Milholland, R. D. 1977. Sclerotium germination and histopathology of Monilinia vacciniicorymbosi on highbush blueberry. Phytopathology 67:848-854.

13. O'Brien, R. R., and van Bruggen, A. H. C. 1992. Accuracy, precision and correlation to yield loss of disease severity scales for corky root of lettuce. Phytopathology 82:9196.

14. Shinners, T. C., and Olson, A. R. 1996. The gynoecial infection pathway of Monilinia vaccinii-corymbosi in lowbush blueberry (Vaccinium angustifolium). Can. J. Plant Sci. 76:493-497.

15. Subbarao, K. V., Dacuyan, S., Koike, S. T., and Jackson, L. E. 1994. Evaluation of three quantitative assays for Sclerotinia minor. Phytopathology 84:1471-1475. 